\title{
MODEL PEMBELAJARAN KOLABORATIF SEBAGAI ALTERNATIF PEMBELAJARAN ILMU PENGETAHUAN SOSIAL
}

\section{COLLABORATIVE LEARNING MODEL AS ALTERNATIVE LEARNING ON SOCIAL SCIENCE}

\author{
S Susantia, T Prasetyo ${ }^{1}$, dan SA Nasution ${ }^{1}$ \\ 1 Program Studi Pendidikan Guru Sekolah Dasar, Fakultas Keguruan dan Ilmu Pendidikan, \\ Universitas Djuanda Bogor, Jl. Tol Ciawi No. 1 Kotak Pos 35 Ciawi Bogor 16720 \\ a Korespondensi: Santi Susanti, Email: sansantisusanti@gmail.com \\ (Diterima: 10-12-2017; Ditelaah: 11-12-2016; Disetujui: 23-02-2017)
}

\begin{abstract}
This study aims to describe the influences of collaborative learning on social sciences learning outcomes. One of the factors of low learning outcomes due to learning that is still focused on teachers (teacher-centered learning). The method used in this study is quasi experimental with nonequivalent control group design. This study used purposive sampling technique with population of class V students of SDN Leuwinutug 04 . The analysis results by using independent sample t-test showed sig value $0,00<0,05$ means that Ho is rejected and $\mathrm{H}_{1}$ accepted. Therefore, it can be concluded that collaborative learning had significant influences on social sciences learning outcomes of class V students of SDN Leuwinutug 04.
\end{abstract}

Keywords: collaborative learning, learning outcomes, social sciences.

\begin{abstract}
ABSTRAK
Penelitian ini bertujuan untuk menggambarkan pengaruh pembelajaran kolaboratif terhadap hasil belajar IPS. Salah satu faktor rendahnya hasil belajar karena pembelajaran yang masih berpusat pada pendidik. Metode yang digunakan dalam penelitian ini adalah eksperimen semu dengan desain nonequivalent control group. Penelitian ini menggunakan teknik purposive sampling dengan populasi peserta didik kelas V SDN Leuwinutug 04. Hipotesis yang digunakan dengan menggunakan independent sample t-test dengan nilai sig $0,000<0,05$ artinya $\mathrm{H}_{0}$ ditolak dan $\mathrm{H}_{1}$ diterima. Jadi, kesimpulan pada penelitian ini adalah pembelajaran kolaboratif berpengaruh secara signifikan terhadap hasil belajar IPS kelas V SDN Leuwinutug 04.
\end{abstract}

Kata kunci: hasil belajar, IPS, pembelajaran kolaboratif.

Susanti S, T Prasetyo, dan SA Nasution. 2017. Model pembelajaran kolaboratif sebagai alternatif pembelajaran Ilmu Pengetahuan Sosial. Didaktika Tauhidi Jurnal Pendidikan Guru Sekolah Dasar 4(1): 19-30.

\section{PENDAHULUAN}

Pendidikan adalah salah satu aspek yang penting dalam kehidupan manusia, pendidikan dimaknai sebagai proses mengubah tingkah laku peserta didik agar menjadi manusia dewasa yang mampu hidup mandiri dan sebagai anggota masyarakat dalam lingkungan alam sekitar dimana individu itu berada (Sagala 2013). Pendidikan diberikan sesuai dengan tahap perkembangan peserta didik. Pendidikan terbagi atas beberapa tingkatan yaitu: 1) pendidikan dasar; 2) pendidikan menengah 
pertama; 3) pendidikan menengah atas; dan 4) pendidikan tinggi. Pendidikan dasar bertujuan memberikan bekal kemampuan dasar kepada peserta didik untuk mengembangkan kehidupannya sebagai pribadi (Imron 2003). Pendidikan dasar menjadi tahap awal dalam pembentukan pribadi, pengetahuan, sikap, dan keterampilan peserta didik agar kelak peserta didik siap melanjutkan pendidikan ke tingkat selanjutnya.

Beberapa unsur yang mendukung tercapainya tujuan pendidikan yaitu pendidik, peserta didik, kurikulum, sarana dan prasarana, ruang belajar dan materi pelajaran. Materi pelajaran merupakan isi atau bahan yang akan dipelajari oleh peserta didik harus dipersiapkan dengan baik untuk disampaikan kepada peserta didik (Susanto 2013). Salah satu pelajaran yang diajarkan di SD adalah pelajaran Ilmu Pengetahuan Sosial (IPS). Tujuan pembelajaran dalam IPS yaitu mempersiapkan peserta didik agar mampu hidup di lingkungan masyarakat dengan baik. Pembelajaran IPS SD harus disesuaikan dengan karakteristik usia peserta didik (Hartati dalam Mujahidin et al., 2016). Syah (2015) menjelaskan perkembangan peserta didik pada jenjang sekolah dasar berusia 7-11 tahun tergolong dalam tahap operasional konkrit, artinya peserta didik baru mampu berfikir sistematis mengenai benda-benda konkrit. Oleh karena itu, pendidik harus membantu peserta didik dalam proses pembelajaran untuk memahami materi ajar yang disampaikan.

Berdasarkan hasil wawancara yang dilakukan dengan pendidik kelas V SDN Leuwinutug 04 ditemukan beberapa fakta menarik berikut: (1) peserta didik tidak tertarik dengan pembelajaran IPS karena materi ajar yang kompleks dan padat meliputi peristiwa-peristiwa, sejarah, nama tokoh yang harus dikuasai peserta didik; (2) materi ajar IPS menuntut peserta didik mengingat, memahami, dan mengaplikasikan setiap kejadian dan peristiwa dalam belajar menyebabkan peserta didik merasa sulit dalam belajar; (3) ketika pembelajaran berlangsung peserta didik merasa mengantuk karena pembelajaran IPS dianggap membosankan; (4) model pembelajaran yang digunakan pendidik adalah ceramah dan tanya jawab; (5) alat peraga yang digunakan masih yang ada di kelas.

Berdasarkan observasi langsung peneliti pada pembelajaran IPS di kelas terlihat rendahnya aktifitas belajar, hal ini dibuktikan sebagai berikut: (1) peserta didik masih pasif dalam pembelajaran dibuktikan dengan tidak ada pertanyaan yang diajukan kepada pendidik; (2) pembelajaran berpusat pada pendidik dibuktikan dengan model yang digunakan saat pembelajaran adalah ceramah; (3) sumber belajar masih terbatas sehingga peserta didik lebih banyak mencatat materi ajar. Permasalahan yang diungkapkan dapat diindikasikan menjadi penyebab rendahnya hasil belajar peserta didik pada mata pelajaran IPS. Dengan demikian, pendidik perlu memperbaharui model pembelajaran yang digunakan pada pelajaran IPS dengan model pembelajaran yang menarik, menyenangkan dan menitikberatkan kegiatan belajar pada peserta didik. Salah satu model pembelajaran yang menekankan pada kegiatan peserta didik dalam belajar adalah model pembelajaran kolaboratif, menyajikan pembelajaran yang membentuk kelompok kecil dalam belajar. Pembelajaran kolaboratif adalah pembelajaran yang dilakukan dua orang atau lebih untuk berbagi pengetahuan, dalam sebuah interaksi sosial untuk meningkatkan 
performans baik keterampilan maupun sikap melalui kegiatan kerja sama secara kelompok (Prasetyo dalam Mujahidin et al., 2016). Pembelajaran dengan model kolaboratif memudahkan peserta didik belajar dan bekerja sama, saling menyumbangkan pikiran dan bertanggung jawab terhadap pencapaian hasil belajar secara kelompok maupun individu. Menurut peneliti pembelajaran kolaboratif belum banyak digunakan oleh pendidik di sekolah dasar dan belum banyak penelitian yang dilakukan mengenai pengaruh model pembelajaran kolaboratif.

\section{MATERI DAN METODE}

\section{Materi}

Belajar menurut Reber dalam Dictionary of Psychology, mengatakan bahwa belajar adalah "The process of acquiring knowledge" proses memperoleh pengetahuan (Syah 2015). Kemudian R. Gagne berpendapat bahwa belajar didefinisikan sebagai suatu proses dimana suatu organisme berubah perilakunya sebagai akibat pengalaman (Susanto 2013). Oleh karena itu, dapat disimpulkan bahwa belajar merupakan sebuah proses memperoleh pengetahuan melalui pengalaman dan latihan yang menyebabkan terjadi perubahan tingkah laku, dan pemahaman manusia dalam aspek pengetahuan, keterampilan dan sikap.

Pembelajaran adalah proses, cara, perbuatan menjadikan orang atau makhluk hidup untuk belajar (Koswara dan Halimah 2008). Menurut Dimyati dan Mudjiyono pembelajaran adalah kegiatan pendidik secara terprogram dalam desain instruksional untuk membuat peserta didik belajar secara aktif, yang menekankan penyediaan sumber belajar (Sagala 2013). Pembelajaran dapat diartikan sebagai proses pelaksanaan belajar dengan melibatkan pendidik, peserta didik, dan kurikulum, untuk mencapai tujuan pendidikan. Pembelajaran merupakan sebuah kegiatan mental dan fisik yang melibatkan interaksi antara pendidik dan peserta didik, adanya kurikulum dan bahan ajar untuk mencapai tujuan pendidikan.

Hasil belajar diperoleh melalui kegiatan belajar. Hakikatnya, hasil merupakan sesuatu yang diusahakan. Oleh karena itu hasil belajar didapatkan setelah peserta didik melaksanakan proses belajar. Berdasarkan pendapat ahli, hasil belajar adalah perubahan-perubahan yang terjadi pada diri siswa baik menyangkut aspek kognitif, afektif dan psikomotorik sebagai hasil dari kegiatan belajar (Susanto 2013).

Hasil belajar dilakukan untuk mengukur tingkat pemahaman peserta didik berdasarkan materi yang telah diajarkan. Kingsley membagi hasil belajar menjadi tiga macam, yaitu: (1) keterampilan dan kebiasaan; (2) pengetahuan dan pengertian; (3) sikap dan cita-cita (Susanto 2013). Sehingga, dapat disimpulkan bahwa hasil belajar adalah capaian keberhasilan peserta didik setelah menjalani proses pembelajaran berupa perubahan pada peserta didik meliputi aspek kognitif, afektif, dan psikomotorik sesuai dengan tujuan pembelajaran yang telah ditentukan. Penilaian hasil belajar dalam IPS terbagi dalam tiga aspek, sebagaimana dikemukakan Sapriya (2009) bahwa pendidikan IPS di sekolah bertujuan untuk mempersiapkan para peserta didik sebagai warga negara yang menguasai pengetahuan (knowledge), keterampilan (skills), sikap dan nilai (attitudes and values) yang digunakan untuk memecahkan masalah pribadi atau masalah sosial serta kemampuan mengambil keputusan dan berpartisipasi dalam berbagai kegiatan kemasyarakatan 
agar menjadi warga negara yang baik. Maka, disimpulkan hasil belajar IPS adalah perubahan yang diperoleh peserta didik setelah melaksanakan pembelajaran IPS meliputi pengetahuan, keterampilan, sikap dan nilai yang menjadi indikator keberhasilan seseorang dalam pembelajaran IPS. Hasil belajar IPS berguna untuk merencanakan tindakan selanjutnya agar tercapai tujuan pembelajaran yang diinginkan. Hasil belajar IPS diharapkan mampu membantu siswa memecahkan masalah-masalah sosial dan dapat hidup bermasyarakat.

Model pembelajaran kolaboratif adalah pembelajaran yang didesain yang melibatkan kerja sama antar peserta didik dalam belajar untuk mencapai tujuan pembelajaran. Hal ini didukung oleh pendapat Sato, pembelajaran kolaboratif adalah pembelajaran yang dilaksanakan dalam kelompok, namun tujuannya bukan untuk mencapai kesatuan yang didapat melalui kegiatan kelompok. Namun, peserta didik dalam kelompok didorong untuk menemukan beragam pendapat atau pemikiran yang dikeluarkan oleh tiap individu dalam kelompok (Widjayanti 2008).

Pembelajaran kolaboratif menekankan pada proses pembelajaran secara bersamasama antar peserta didik. Senada dengan pendapat Wiersma bahwa "collaborative learning is philosophy: working together, building together, learning together, improving together". Pembelajaran kolaboratif memiliki filosofi belajar bersama, bekerja sama, membangun pengetahuan bersama, melakukan perubahan pengetahuan bersama, dan mengalami peningkatan bersama-sama" (Widjayanti 2008). Adapun pada penelitian ini, langkah yang digunakan berdasarkan pendapat Bill yang dikutip Prasetyo
(Mujahidin et al. 2016) sebagai berikut: 1) menyusun tugas pembelajaran kolaboratif (structuring collaborative learning tasks); 2) berorientasi dan pelatihan peserta didik berpartisipasi (orienting and training students to participate); 3) pembentukan grup (forming groups); 4) memfasilitasi peserta didik kolaborasi (facilitating students collaboration); 4) mengevaluasi peserta didik dalam situasi pembelajaran kolaboratif (evaluating students in collaborative learning situations).

Kelebihan model pembelajaran kolaboratif yang diungkapkan oleh Gokhale (1995) sebagai berikut: 1) helped understanding, membantu peserta didik dalam menemukan suatu pemahaman dalam pembelajaran; 2) pooled knowledge and experience, pembelajaran kolaboratif memberikan pengetahuan dan pengalaman belajar bersama-sama bagi peserta didik; 3) got helpful feedback, membantu peserta didik menemukan umpan balik atau stimulus dalam belajar; 4) stimulated thingking, pembelajaran kolaboratif dapat merangsang pemikiran peserta didik agar dapat berpikir kritis; 5) got new perspectives, peserta didik mendapatkan perspektif baru dalam pembelajaran; 6) more relaxed atmosphere, makes problem solving easy, suasana yang nyaman dalam pembelajaran akan membuat pemecahan masalah menjadi lebih mudah; 7) fun learning, memberikan pembelajaran yang menyenangkan bagi peserta didik; 8) greater responsibility for my self and the group, peserta didik akan memiliki rasa tanggung jawab yang besar terhadap diri sendiri maupun kelompok; 9) made new friends, peserta didik mendapatkan teman yang baru, karena pembelajaran yang dilakukan secara berkelompok.

Berdasarkan pandangan Islam, manusia sebagai makhluk sosial pasti memerlukan 
bantuan orang lain dalam kehidupannya. Oleh karena itu, manusia harus mampu berkolaborasi dengan lingkungan sekitar. Pembelajaran kolaboratif mengarahkan peserta didik untuk bekerja sama dalam belajar, mencari dan menemukan tujuan pembelajaran yang hendak dicapai. Kolaboratif atau kerjasama jika diterjemahkan dalam Bahasa Arab memberikan beberapa makna dan diantaranya adalah Ta'awun (Abdussalam 2014). Perintah saling bekerja sama tertulis dalam firman Allah surah Al-Maidah: 2 sebagai berikut. "Dan tolong menolonglah kamu dalam (mengerjakan) kebajikan dan takwa, dan jangan tolong menolong dalam berbuat dosa dan permusuhan. Bertakwalah kepada Allah. Sungguh, Allah sangat berat siksanya." (Departemen Agama RI 2009).

Berkenaan dengan hal ini, Rasulullah SAW telah menjelaskan pentingnya prinsip kerja sama dalam rangka mencapai tujuan dakwah Islamiyah dan penyebarannya diseluruh pelosok dunia (Nizar dan Syaifudin 2010). Bekerja sama yang diperintahkan Allah Swt, dan Rasulullah
Saw, merupakan bekerja sama dalam hal mencapai kebaikan, salah satunya dalam belajar berkolaborasi.

\section{Metode}

\section{Metode Penelitian}

Metode penelitian yang digunakan dalam penelitian ini adalah jenis eksperimen semu dengan Nonequivalent Control Group Design yang terdapat dua kelompok yaitu kelompok kontrol dan eksperimen.

\section{Populasi dan Sampel}

Populasi dalam penelitian ini adalah seluruh peserta didik kelas V SDN Leuwinutug 04. Sampel yang digunakan melalui purposive sampling atau dengan mengambil sampel melalui tujuan tertentu. Sampel terdiri dari kelompok kontrol kelas VB dan kelompok eksperimen kelas VA berjumlah 60 peserta didik.

\section{Definisi Konseptual dan Operasional}

Adapun definisi konseptual dan operasional pada penelitian ini terdapat pada Tabel 1.

Tabel 1 Definisi konseptual dan operasional penelitian

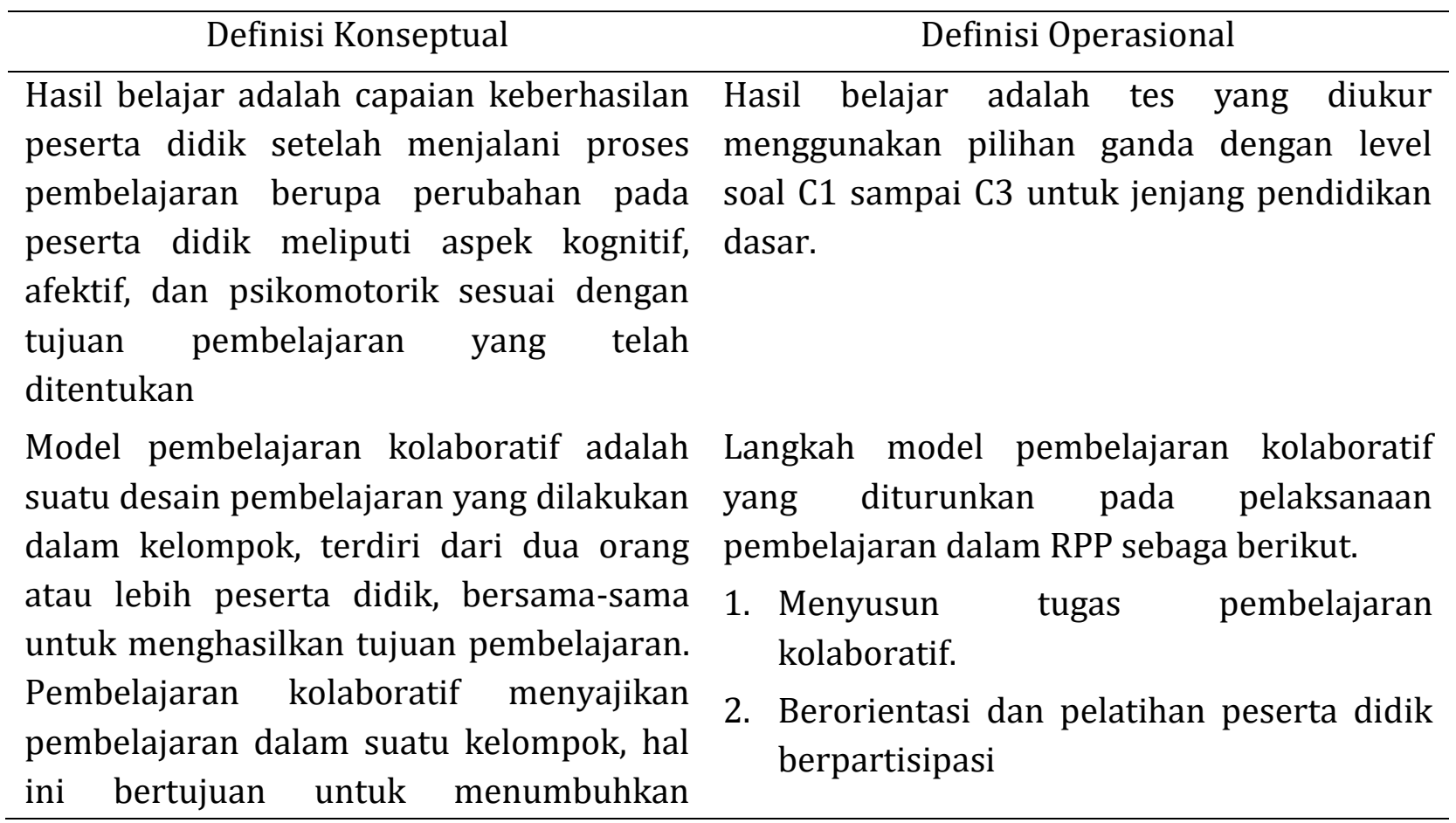


partisipasi peserta didik dalam belajar 3. Pembentukan grup bersama.

4. Memfasilitasi peserta didik kolaborasi

5. Mengevaluasi peserta didik dalam situasi pembelajaran kolaboratif

\section{Teknik Pengumpulan Data}

Teknik pengumpulan data pada penelitian ini adalah dengan melakukan wawancara, observasi, dan tes. Wawancara dilakukan kepada pendidik dan peserta didik kelas $\mathrm{V}$ SDN Leuwinutug 04. Observasi dilakukan untuk melihat pra penelitian peserta didik sebelum diberi perlakuan tertentu. Tes dilakukan dua kali yaitu tes awal (pretest) dan tes akhir (posttest), tes diberikan dengan jenis pilihan ganda. Instrumen pengumpulan data yang digunakan dalam penelitian ini adalah pedoman wawancara, tes pilihan ganda, dan lembar observasi pembelajaran di kelas. Sebelum peneliti memberikan tes hasil belajar, maka peneliti menguji coba instrumen untuk mengetahui kualitas instrumen terutama validitas dan estimasi reliabilitas. Uji validitas instrumen pilihan ganda yang digunakan adalah validitas isi (Content Validity) oleh pakar, selanjutnya diuji cobakan kepada kelas VI pada sekolah yang sama. Uji validitas dilakukan menggunakan point biserial dengan jumlah soal 30, kemudian dihasilkan soal valid berjumlah 16 butir soal. Adapun data hasil uji validitas dapat dilihat pada Tabel 2.

Adapun estimasi reliabilitas menggunakan KR-20 sebesar 0,850. Jadi, dapat disimpulkan bahwa butir soal yang telah disusun adalah valid dan reliabel. Selanjutnya, uji hipotesis statistik dilakukan dengan bantuan SPSS 21.0 dengan kriteria keputusan Ho ditolak jika nilai sig p-value lebih kecil dari 0,05. Berikut ajuan hipotesis statistik penelitian sebagai berikut.

$\mathrm{H}_{o}: \mu_{e}=\mu_{k}$ (rata-rata nilai postes pada kelas eksperimen sama dengan kelas kontrol).

$\mathrm{H}_{0}: \mu_{e} \neq \mu_{k}$ (rata-rata nilai postes pada kelas eksperimen lebih tinggi dari kelas kontrol).

Tabel 2 Validitas empiris tes pilihan ganda

\begin{tabular}{crrl}
\hline Butir Soal & rpbi & r tabel & Keterangan \\
\hline 1 & 0,484 & 0,423 & Valid \\
2 & $-0,132$ & 0,423 & Tidak Valid \\
3 & 0,488 & 0,423 & Valid \\
4 & 0,361 & 0,423 & Tidak Valid \\
5 & $-0,410$ & 0,423 & Tidak Valid \\
6 & $-0,026$ & 0,423 & Tidak Valid \\
7 & 0,311 & 0,423 & Tidak Valid \\
8 & 0,436 & 0,423 & Valid \\
9 & 0,801 & 0,423 & Valid \\
10 & 0,515 & 0,423 & Valid \\
11 & $-0,049$ & 0,423 & Tidak Valid \\
12 & 0,428 & 0,423 & Valid \\
13 & 0,572 & 0,423 & Valid \\
14 & 0,430 & 0,423 & Valid \\
15 & 0,841 & 0,423 & Valid \\
16 & 0,678 & 0,423 & Valid \\
17 & 0,218 & 0,423 & Tidak Valid \\
18 & 0,454 & 0,423 & Valid \\
19 & 0,378 & 0,423 & Tidak Valid \\
20 & 0,402 & 0,423 & Tidak Valid \\
21 & 0,768 & 0,423 & Valid \\
22 & 0,288 & 0,423 & Tidak Valid \\
23 & 0,517 & 0,423 & Valid \\
24 & 0,417 & 0,423 & Tidak Valid \\
25 & $-0,080$ & 0,423 & Tidak Valid \\
26 & 0,249 & 0,423 & Tidak Valid \\
27 & 0,429 & 0,423 & Valid \\
28 & -1029 & 0,423 & Tidak Valid \\
29 & 0,611 & 0,423 & Valid \\
30 & 0,579 & 0,423 & Valid \\
\hline & & &
\end{tabular}




\section{HASIL DAN PEMBAHASAN}

\section{Hasil}

SDN Leuwinutug 04 merupakan sebuah lembaga pendidikan yang berdiri di tengah kawasan industri. SDN Leuwinutug 04 berdiri sejak 1983 setelah SDN Leuwinutug 01, 02, dan 03. SDN Leuwinutug 04 terdiri dari kelas 1 sampai kelas 6 memiliki masing-masing 2 rombel.

Penelitian ini dilakukan selama 4 bulan terhitung mulai pada bulan Desember 2016 sampai Maret 2017. Penelitian ini terdiri dari 6 kali pertemuan, yakni satu kali pertemuan peneliti mengambil data pretest IPS sebelum diberi perlakuan, proses perlakuan terdiri dari empat pertemuan, dan terakhir peneliti mengambil data posttest IPS setelah diberi perlakuan. Pertemuan kelas eksperimen dan kontrol dilakukan secara bergantian. Pada penelitian ini, peneliti melakukan persiapan diantaranya: (1) membuat perangkat pembelajaran terdiri dari silabus, RPP, alat peraga, (2) membuat pedoman observasi pada kelas kontrol dan kelas eksperimen, dan (3) tes hasil belajar untuk kelas eksperimen dan kelas kontrol. RPP disesuaikan menggunakan model pembelajaran kolaboratif untuk kelas eksperimen dan RPP kelas kontrol menggunakan model pembelajaran klasikal.

Hasil penelitian data yang disajikan secara deskriptif kelas eksperimen dan kontrol antara lain: (a) pretest dan (b) posttest.

\section{Pretest}

Skor pretest diperoleh sebelum peneliti memberikan perlakuan pada kelompok eksperimen dan kelompok kontrol. Adapun deskriptif statistik pretest yang diperoleh dapat dilihat pada Tabel 3.
Tabel 3 Deskriptif statistik pretest IPS

\begin{tabular}{lrlr}
\hline \multicolumn{2}{c}{ Eksperimen } & \multicolumn{2}{c}{ Kontrol } \\
\hline \multicolumn{1}{c}{$\mathrm{N}$} & \multicolumn{1}{c}{30} & $\mathrm{~N}$ & \multicolumn{1}{c}{30} \\
\hline Minimum & 19 & Minimum & 25 \\
Maximum & 69 & Maximum & 69 \\
Mean & 43,4 & Mean & 43,3 \\
Median & 42,125 & Median & 42,1 \\
Modus & 40,35 & Modus & 35,16 \\
Varians & 206,31 & Varians & 131,54 \\
Std. Deviasi & 14,36 & Std. Deviasi & 11,46 \\
\hline
\end{tabular}

Sementara itu, skor hasil pretest kelompok eksperimen lebih jelas dapat dilihat dalam Tabel 4.

Tabel 4 Distribusi frekuensi pretest IPS kelas eksperimen

\begin{tabular}{ccr}
\hline No & Interval & Frekuensi \\
\hline 1 & $19-27$ & 5 \\
2 & $28-36$ & 5 \\
3 & $37-45$ & 8 \\
4 & $46-54$ & 4 \\
5 & $55-63$ & 5 \\
6 & $64-72$ & 3 \\
Jumlah & & 30 \\
\hline
\end{tabular}

Adapun hasil pretest kelompok kontrol terdapat dalam Tabel 5.

Tabel 5 Distribusi frekuensi pretest IPS kelas kontrol

\begin{tabular}{ccr}
\hline No & Interval & Frekuensi \\
\hline 1 & $25-32$ & 8 \\
2 & $33-40$ & 6 \\
3 & $41-48$ & 5 \\
4 & $49-56$ & 7 \\
5 & $57-64$ & 3 \\
6 & $65-72$ & 1 \\
Jumlah & & 30 \\
\hline
\end{tabular}


Paparan uji prasyarat pada penelitian ini dapat disajikan sebagai berikut.

\section{Uji prasyarat}

Hasil uji normalitas pretest kelompok eksperimen dengan kriteria keputusan Ho diterima jika $x_{\text {hitung }}^{2}<x_{\text {tabel }}^{2}$, dengan signifikansi 5\% $(\alpha=0,05)$ lebih jelas dapat dilihat pada Tabel 6 .

Tabel 6 Uji normalitas pretes

\begin{tabular}{llcl}
\hline Sumber Data & $x_{\text {hitung }}^{2}$ & $x_{\text {tabel }}^{2}$ & Keputusan \\
\hline Eksperimen & 3,938 & 11,070 & Normal \\
Kontrol & 5,702 & 11,070 & Normal \\
\hline
\end{tabular}

Berdasarkan perhitungan Chi Kuadrat $\left(x^{2}\right)$ yang tertera dalam Tabel 5 adalah $x_{\text {hitung }}^{2}<x_{\text {tabel }}^{2}$. $x_{\text {tabel }}^{2}$ didapatkan dari $\mathrm{dk}=\mathrm{k}-1$ dengan $\mathrm{k}$ banyak kelas atau kelompok interval. $\mathrm{Dk}=6-1=5$ maka $x_{\text {tabel }}^{2}=11,070 . \quad$ sehingga dapat disimpulkan bahwa data pretest kelompok eksperimen dan kelompok kontrol berdistribusi normal.

Hasil uji homogenitas pretest hasil belajar IPS tersaji pada Tabel 7.

Tabel 7 Uji homogenitas pretest IPS

\begin{tabular}{lcccc}
\hline \hline Sumber Data & $S^{2}$ & Fhitung & Ftabel & Keputusan \\
\hline Eksperimen & 206.31 & & & \\
Kontrol & 143.00 & 1,442 & 1,84 & Homogen \\
\hline
\end{tabular}

Berdasarkan Tabel 7, Fhitung diperoleh dengan membandingkan varians terbesar dengan varians terkecil sehingga diperoleh Fhitung 1,442, kemudian membandingkan dengan Ftabel dengan rumus $\mathrm{dk}_{\text {pembilang }}=$ $\mathrm{n}-1=30-1=29$ (varians terbesar) dan $\mathrm{dk}_{\text {penyebut }}=\mathrm{n}-1=30-1=29$ (varians terkecil) dengan taraf signifikansi $5 \%$ maka diperoleh Ftabel 1,84 sehingga dengan kriteria pengujian Fhitung $<$ Ftabel, maka
1,442 < 1,84 yang berarti Ho diterima dan data pretes memiliki varians yang homogen.

\section{Posttest}

Data posttest IPS kelompok eksperimen terdapat dalam Tabel 8.

Tabel 8 Deskriptif statistik posttest IPS

\begin{tabular}{lrlr}
\hline \multicolumn{2}{c}{ Eksperimen } & \multicolumn{2}{c}{ Kontrol } \\
\hline \multicolumn{1}{c}{$\mathrm{N}$} & \multicolumn{1}{c}{30} & \multicolumn{1}{c}{$\mathrm{N}$} & \multicolumn{1}{c}{30} \\
\hline Minimum & 50 & Minimum & 25 \\
Maximum & 94 & Maximum & 81 \\
Mean & 70,58 & Mean & 56,83 \\
Median & 72,35 & Median & 56,72 \\
Modus & 75,96 & Modus & 57,83 \\
Varians & 113,58 & Varians & 206,31 \\
Std. Deviasi & 10,65 & Std. Deviasi & 14,36 \\
\hline
\end{tabular}

Skor posttest IPS pada kelompok eksperimen tersaji pada Tabel 9. Adapun skor postes IPS kelompok kontrol terdapat dalam Tabel 10.

Tabel 9 Distribusi frekuensi posttest kelompok eksperimen

\begin{tabular}{ccr}
\hline No & Interval & Frekuensi \\
\hline 1 & $50-57$ & 5 \\
2 & $58-65$ & 4 \\
3 & $66-73$ & 7 \\
4 & $74-81$ & 11 \\
5 & $82-89$ & 2 \\
6 & $90-97$ & 1 \\
Jumlah & & 30 \\
\hline
\end{tabular}

\section{Uji Hipotesis Statistik}

Hasil analisis output uji one sample t-test posttest IPS tersaji pada Tabel 10. Berdasarkan Tabel 11, diperoleh nilai signifikansi 0,001<0,05. Dengan demikian, Ho ditolak artinya terdapat pengaruh model 
pembelajaran kolaboratif terhadap hasil belajar IPS secara signifikan.

Tabel 10 Distribusi frekuensi posttest kelompok kontrol

\begin{tabular}{ccr}
\hline No & Interval & Frekuensi \\
\hline 1 & $25-34$ & 1 \\
2 & $35-44$ & 6 \\
3 & $45-54$ & 6 \\
4 & $55-64$ & 9 \\
5 & $65-74$ & 3 \\
6 & $75-84$ & 5 \\
Jumlah & & 30 \\
\hline
\end{tabular}

Tabel 11 Uji one sample t-test posttest IPS kelompok eksperimen

\begin{tabular}{rrr}
\hline T & Df & Sig. (2-tailed) \\
\hline 3.720 & 29 & 0,001 \\
\hline
\end{tabular}

Adapun hasil uji one sample t-test postes IPS kelompok kontrol tersaji pada Tabel 12.

Tabel 12 Uji one sample t-test posttest IPS kelompok kontrol

\begin{tabular}{lrr}
\hline \multicolumn{3}{c}{ Test Value $=63,75$} \\
\hline $\mathrm{T}$ & Df & \multicolumn{2}{c}{ Sig. (2-tailed) } \\
\hline-2.949 & 29 & 0,006 \\
\hline
\end{tabular}

Berdasarkan Tabel 12, diperoleh nilai signifikansi 0,006 < 0,05. Dengan demikian, Ho ditolak artinya terdapat pengaruh model pembelajaran konvensional terhadap hasil belajar IPS secara signifikan. Selanjutnya, hasil pengujian one sample t-test, perlakuan pada kelompok eksperimen dan kelompok kontrol berpengaruh terhadap hasil belajar IPS. Dengan demikian, peneliti melakukan uji lanjut dengan uji statistik independent sample t-test melalui bantuan SPSS jenis 21.0. Adapun hasil uji lanjut independent sample t-test posttest IPS terdapat pada Tabel 13.
Berdasarkan Tabel 13, diperoleh nilai sig (2-tailed) 0,000 < 0,05. Maka, Ho ditolak yang artinya kelompok eksperimen lebih baik dalam memberikan pengaruh dibandingkan kelompok kontrol. Jadi, dapat disimpulkan bahwa terdapat pengaruh model pembelajaran kolaboratif terhadap hasil belajar IPS.

Tabel 13 Uji lanjut independent sample t-test posttest IPS

\begin{tabular}{lr}
\hline & Sig. (2-tailed) \\
\hline Equal variances assumed & 0,000 \\
$\begin{array}{l}\text { Equal variances not } \\
\text { assumed }\end{array}$ & 0,000 \\
\hline
\end{tabular}

\section{Pembahasan}

Penelitian ini merupakan penelitian eksperimen dengan desain Nonequivalent Control Group Design, yaitu menempatkan subjek penelitian ke dalam dua kelompok atau kelas yang terbagi menjadi kelompok eksperimen dan kelompok kontrol. Kelompok eksperimen menjadi kelompok yang diberikan perlakuan atau treatment dan kelompok kontrol sebagai kelompok pembanding. Treatment yang diberikan pada kelompok eksperimen adalah model pembelajaran kolaboratif sedangkan kelompok kontrol diberikan perlakuan dengan model pembelajaran konvensional. Tujuan penelitian ini adalah untuk mendeskripsikan pengaruh model pembelajaran kolaboratif terhadap hasil belajar IPS peserta didik kelas V SD Negeri Leuwinutug 04.

Penentuan sampel penelitian kelas VA terpilih sebagai kelompok eksperimen dan VB terpilih sebagai kelompok kontrol. Pada penelitian ini, peneliti berperan sebagai pendidik dan melaksanakan pembelajaran sesuai dengan RPP yang telah dibuat. Penelitian ini dilaksanakan selama enam kali pertemuan, pada pertemuan pertama 
peneliti mengambil data pretes, pertemuan kedua sampai kelima peneliti melaksanakan pembelajaran di kelas, dan pertemuan enam peneliti mengambil data berupa nilai postes IPS.

$\begin{array}{ccr}\begin{array}{c}\text { Kegiatan } \\ \text { eksperimen }\end{array} & \text { pemblajaran di } & \text { kelas } \\ \text { berkelompok. } & \text { Hal ini bertujuan } & \text { untuk }\end{array}$
membangun kerjasama antar peserta didik. Kelompok yang dibentuk merupakan kelompok kecil yang berjumlah tiga orang. Kegiatan pembelajaran yang mengkolaborasikan peserta didik dapat berpengaruh terhadap sikap bekerja sama, belajar bersama, membangun pengetahuan bersama, melakukan perubahan bersama, dan mengalami peningkatan bersama dalam belajar. Pembelajaran yang dilaksanakan di kelas eksperimen menitikberatkan pada kegiatan peserta didik, pendidik berperan sebagai fasilitator yang memfasilitasi dan mengarahkan peserta didik dalam melaksanakan kolaborasi atau kerja sama.

Model pembelajaran kolaboratif menitikberatkan pada pembelajaran yang berpusat pada peserta didik untuk belajar bersama-sama dan bekerja sama membangun pengetahuan sebagaimana pendapat Wiersma yang mengemukakan filosofi pembelajaran kolaboratif adalah bekerja sama, belajar bersama, membangun pengetahuan bersama, melakukan perubahan bersama dan mengalami peningkatan bersama-sama. Pembelajaran kolaboratif membandingkan upaya kompetitif dan individu, memiliki banyak manfaat dan menghasilkan prestasi yang lebih tinggi dan produktivitas yang lebih besar, lebih peduli, suportif dan berkomitmen, kesehatan psikologis baik, kompetensi sosial, dan harga diri (Laal dan Ghodsi 2012).

Hasil penelitian menunjukkan model pembelajaran kolaboratif pada kelompok eksperimen yang menunjukkan peningkatan, yaitu rata-rata pretest kelompok eksperimen 43,4 menjadi 70,58. Adapun pada kelompok kontrol pembelajaran dilakukan dengan menggunakan model pembelajaran klasikal melalui metode ceramah, tanya jawab, diskusi, dan demonstrasi. Pada kelompok kontrol hasil skor pretest dan posttest kelompok kontrol yaitu pretest 42,9 dan posttest 56,83. Peningkatan kelompok eksperimen terlihat lebih signifikan dibandingkan kelompok kontrol. Artinya, model pembelajaran kolaboratif berpengaruh terhadap hasil belajar IPS kelas V SD Negeri Leuwinutug 04.

Uji hipotesis dilakukan menggunakan one sample t-test melalui program SPSS 21.0. Uji hipotesis digunakan untuk melihat ada atau tidak pengaruh suatu model pembelajaran terhadap hasil belajar IPS antara kelompok eksperimen dan kelompok kontrol. Berdasarkan hasil analisis uji statistik one sample t-test pada kelompok eksperimen memperoleh sig 0,001<0,05. Artinya Ho ditolak dengan kesimpulan terdapat pengaruh model pembelajaran kolaboratif terhadap hasil belajar IPS. Adapun uji hipotesis statistik pada kelompok kontrol menujukan sig 0,006 $<0,05$, dengan kesimpulan Ho ditolak dan terdapat pengaruh model pembelajaran klasikal terhadap hasil belajar IPS.

Berdasarkan pembelajaran yang telah diuraikan, kelompok eksperimen dan kelompok kontrol adalah sama-sama terdapat pengaruh. Hasil analisis data dengan uji independent sampel t-test menunjukkan sig (2 tailed) adalah 0,000. Jika dibandingkan taraf signifikansi $\alpha=0,05$, maka sig $0,000<0,05$. Sehingga dapat disimpulkan Ho ditolak dan H1 diterima, artinya kelompok eksperimen memberikan 
pengaruh positif yang lebih baik dibandingkan kelompok kontrol.

Wheeler, Yeomans, dan Wheeler (2008) menjelaskan bahwa "kolaborasi bukan kompetisi tetapi harus ditekankan pada tujuan utama. Peserta didik didorong untuk berkontribusi pada pembelajaran di kelas, berbagi pikiran, sumber daya yang berguna bagi peserta didik, dan penemuan peserta didik. Guru harus bertindak sebagai moderator bukan instruktur, dan perlu menahan diri dari tindakan langsung dalam rangka memberikan kebebasan dan demokrasi kepada peserta didik". Hal ini sesuai dengan faktor-faktor yang menyebabkan pembelajaran kolaboratif berpengaruh signifikan terhadap hasil belajar IPS peserta didik antara lain: 1) peserta didik menjadi lebih aktif dalam pembelajaran; 2) peserta didik saling belajar bersama dan bekerja sama dalam pembelajaran; 3) peserta didik menjadi lebih percaya diri dalam belajar; 4) terciptanya kondisi belajar yang menyenangkan bagi peserta didik karena belajar secara berkelompok dan saling membantu dalam belajar.

Sebagaimana pendapat Bimpe et al. (2017) bahwa pembelajaran kooperatif memberikan ruang kepada seluruh peserta didik untuk dapat saling berkontribusi dan berpartisipasi dalam kegiatan pembelajaran di kelas. Peran pendidik dalam pembelajaran di kelas adalah membangkitkan sikap berpartisipasi peserta didik dalam belajar, mengingat tidak semua peserta didik dapat berpartisipasi maupun ikut berkontribusi dalam belajar. Adapun beberapa perbedaan yang terdapat dalam pembelajaran kolaboratif adalah tidak terjadi persaingan antar peserta didik karena dalam pembelajaran ini peserta didik melakukan belajar dan berdiskusi secara bersama untuk membangun sebuah pengetahuan bersama.

\section{KESIMPULAN DAN IMPLIKASI}

\section{Kesimpulan}

Berdasarkan hasil penelitian dan pembahasan serta hasil uji independent sample t-test dengan taraf signifikansi $5 \%$ diperoleh sig 0,000 $<0,05$ dapat disimpulkan terdapat pengaruh yang signifikan penggunaan model pembelajaran kolaboratif terhadap hasil belajar IPS pada materi Persiapan Kemerdekaan Indonesia dan Perumusan Dasar Negara Kelas V SD Negeri Leuwinutug 04. Pembelajaran kolaboratif mampu menjadi sebuah alternatif bagi pendidik untuk memberikan pembelajaran yang menekankan pada kegiatan yang berpusat pada peserta didik, yang membantu peserta didik untuk belajar bersama, bekerja sama serta mendapat pengetahuan bersama-sama. Pembelajaran kolaboratif memberikan kesempatan kepada peserta didik untuk saling mengenal satu sama lainnya. Selain itu, dengan pembelajaran kolaboratif dapat membangun rasa percaya diri peserta didik, memiliki rasa tanggung jawab, dan sikap bekerja sama.

\section{Implikasi}

Implikasi dari penelitian ini adalah penerapan model pembelajaran kolaboratif diharapkan menjadi alternatif dalam pembelajaran yang digunakan oleh pendidik untuk melakukan pembelajaran yang menarik dan bermakna dengan cara belajar kelompok dan belajar bersama khususnya dalam pembelajaran IPS agar dapat meningkatkan hasil belajar peserta didik, peserta didik diharapkan dapat belajar lebih semangat, dan tertarik kepada 
pembelajaran IPS, meningkatkan kerja sama antar peserta didik serta meningkatkan hasil belajar melalui model pembelajaran kolaboratif. Penerapan model pembelajaran kolaboratif mampu menjadi alternatif model pembelajaran yang berpusat pada peserta didik. Pembelajaran kolaboratif yang diterapkan dalam pembelajaran di kelas, dapat membantu pendidik dalam menyampaikan materi ajar dan peserta didik akan lebih mudah memahami materi ajar yang disampaikan karena saling belajar dan bekerja sama mendapatkan ilmu pengetahuan dan pemahaman.

\section{DAFTAR PUSTAKA}

Bimpe SM, AI Gambari, AK Agboola, dan L Nureni. 2017. Efficacy of podcast on nigeria certificate of education biology students' achievement in individualized and collaborative settings. ATBU Journal of Science, Technology and Education, 4(4), 149-165.

Imron Ali et al. 2003. Manajemen pendidikan. Universitas Negeri Malang, Malang.
Koswara, D Deni, dan Halimah. 2008. Bagaimana menjadi guru kreatif? Pribumi Mekar, Bandung.

Laal M and SM Ghodsi. 2012. Benefits of collaborative learning. Procedia-Social and Behavioral Sciences, 31, pp.486-490.

Mujahidin et al. 2016. Paradigma pendidikan dasar. UIKA Bogor, Bogor.

Nizar S dan M Syaifudin. 2010. Isu-isu kontemporer tentang pendidikan Islam. Kalam Mulia, Jakarta.

Sagala S. 2013. Konsep dan makna pembelajaran. Alfabeta, Bandung.

Sapriya. 2009. Pendidikan IPS konsep dan pembelajaran. Remaja Rosdakarya, Bandung.

Susanto A. 2013. Teori belajar dan pembelajaran di Sekolah Dasar. Kencana, Jakarta.

Syah M. 2015. Psikologi belajar. Rajawali Pers, Jakarta.

Wheeler S, Yeomans, and D Wheeler, 2008. The good, the bad and the wiki: Evaluating student generated content for collaborative learning. British journal of educational technology, 39(6), pp. 987995. 